\section{E-091 STROKE AWARENESS KNOWLEDGE GAP IN WOMEN}

J Campos*, P Lin, L Wang, K NassimiMoghaddam, F Do, J Lee, N Imbre, I Totounji, D Strebig, J Kim, K Golshani, L Lin. Department of Neurosurgery, University of California Invine Medical Center, Orange, CA

\subsection{6/neurintsurg-2019-SNIS.166}

Introduction Understanding current levels of stroke awareness in women may highlight knowledge gaps and areas for targeted education in those most likely to be affected by stroke. The purpose of this study was to evaluate awareness of stroke (i.e. stroke symptoms and risk factors) among women in Orange County. Following baseline assessments in knowledge, educational programs will be implemented as a public health intervention to raise awareness.

Methods An institutional IRB-approved, prospectively collected survey study was conducted among randomly selected English-speaking women, age 18-82 years, throughout a variety of public locations in Orange County, California, between October 2018 to March 2019. Knowledge of stroke awareness was assessed by 6 standardized open-ended questions.

Results A total of 672 women, average age $40.6 \pm 16$ years, responded to the survey. The majority of the participants knew someone who had experienced a stroke, $67.6 \%$ $(n=454)$, yet $30.1 \%(n=202)$ of participants were aware of the two types of stroke, ischemic and hemorrhagic. Of the $21 \%(n=141)$ who correctly identified modifiable lifestyle factors to decrease the risk for stroke, the majority correctly answered blood pressure control. While, 17.4\% $(n=117)$ correctly identified the constellation of common signs and symptoms of stroke, the majority correctly answered slurred speech. Among the age group at highest risk for stroke $(>65$ years), particular knowledge deficits in the benefits of smoking cessation and adequate diabetes management to decrease stroke risk.

Conclusions These preliminary study results indicate a potential and significant lack of women's knowledge of stroke awareness in the Orange County area, despite a majority of survey respondents having a close connection to a stroke patient. Continuation of this project will provide further information on the current knowledge gaps in stroke awareness and highlight concepts for targeted education for those women at greatest risk of stroke.

Tables 1-3, All values are percentages of respondents within the respective age group.

\begin{tabular}{|c|c|c|c|c|c|}
\hline & $\begin{array}{l}\text { Age, } \\
\text { years }\end{array}$ & & & & \\
\hline & $\begin{array}{l}18-24(n= \\
103)\end{array}$ & $\begin{array}{l}25-34 \\
(n=150)\end{array}$ & $\begin{array}{l}35-44 \\
(n=159)\end{array}$ & $\begin{array}{l}45-64 \\
(n=177)\end{array}$ & $\begin{array}{l}>65 \\
(n=59)\end{array}$ \\
\hline Modifiable Stroke Risk Factors & 20 & 29 & 28 & 37 & 27 \\
\hline Warning Signs of Stroke & 11 & 16 & 18 & 19 & 25 \\
\hline $\begin{array}{l}\text { Awareness of stroke type } \\
\text { (ischemic, hemorrhagic) }\end{array}$ & 16 & 15 & 23 & 25 & 25 \\
\hline $\begin{array}{l}\text { Know someone who experienced } \\
\text { a stroke }\end{array}$ & 50 & 59 & 69 & 75 & 92 \\
\hline
\end{tabular}

Abstract E-091 Table 2 Knowledge of Modifiable Risk Factors by Age

\begin{tabular}{llllll}
\hline \multicolumn{5}{l}{ Age, years } \\
\hline Modifiable Stroke Risk & $18-24(n=$ & $25-34$ & $35-44$ & $45-64$ & $>65$ \\
Factor & $103)$ & $(n=150)$ & $(n=159)$ & $(n=177)$ & $(n=59)$ \\
Blood pressure control & 78 & 85 & 83 & 85 & 92 \\
Smoking cessation & 70 & 73 & 80 & 82 & 78 \\
Adequate diabetes & 65 & 72 & 67 & 79 & 76 \\
management & & & & & \\
\hline
\end{tabular}

Abstract E-091 Table 3 Knowledge of at least a sole stroke symptom among women by age

\begin{tabular}{|c|c|c|c|c|c|}
\hline & Age, years & & & & \\
\hline $\begin{array}{l}\text { Warning Sign of } \\
\text { Stroke }\end{array}$ & $\begin{array}{l}18-24(n= \\
103)\end{array}$ & $\begin{array}{l}25-34 \\
(n=150)\end{array}$ & $\begin{array}{l}35-44 \\
(n=159)\end{array}$ & $\begin{array}{l}45-64 \\
(n=177)\end{array}$ & $\begin{array}{l}>65 \\
(n=59)\end{array}$ \\
\hline $\begin{array}{l}\text { Sudden weakness of } \\
\text { face }\end{array}$ & 62 & 61 & 72 & 69 & 75 \\
\hline $\begin{array}{l}\text { Sudden weakness of } \\
\text { limb }\end{array}$ & 71 & 70 & 75 & 77 & 80 \\
\hline Slurred speech & 65 & 79 & 77 & 76 & 83 \\
\hline
\end{tabular}

Disclosures J. Campos: None. P. Lin: None. L. Wang: None. K. NassimiMoghaddam: None. F. Do: None. J. Lee: None. N. Imbre: None. I. Totounji: None. D. Strebig: None. J. Kim: None. K. Golshani: None. L. Lin: 1; C; Stryker. 2; C; Medtronic, MicroVention.

\section{E-092 BRINGING THE TREATMENT TO THE PATIENT: A SINGLE CENTER MOBILE STROKE UNIT EXPERIENCE}

H Shownkeen*, A Lindstrom, H Crumlett, M Mohajer-Esfahani, D Lumb, S Graham. Northwestern Medicine Central Dupage Hospital, Winfield, IL

\subsection{6/neurintsurg-2019-SNIS.167}

Every minute saved in treatment saves a patient one day of disability (Meretoja et al., 2014). In January 2017, a community hospital implemented a mobile stroke unit to decrease time to treatment and improve outcomes for the surrounding community. The goal of the mobile stroke unit is to treat patients as quickly, safely and efficiently as possible. In comparison to conventional EMS treatment the mobile stroke unit has demonstrated a 31 minute improvement in time to thrombolytic therapy $(\mathrm{N}=50)$. Time is measured from alarm to thrombolytic start. An analysis of data from last known well to treatment the mobile stroke unit demonstrates a 42 minute improvement. Treatment in the 'Golden Hour' is especially important as patients treated within 60 minutes of symptom onset have better outcomes. However, less than $1 \%$ of patients are treated within the 60 minute timeframe (Ebinger et al., 2015). In the mobile stroke unit, $29 \%$ of patients are treated within 60 minutes of symptom onset compared to $7 \%$ in the Emergency Department. The goal of improving time to treatment is improving functional outcomes. Sixty-nine percent 